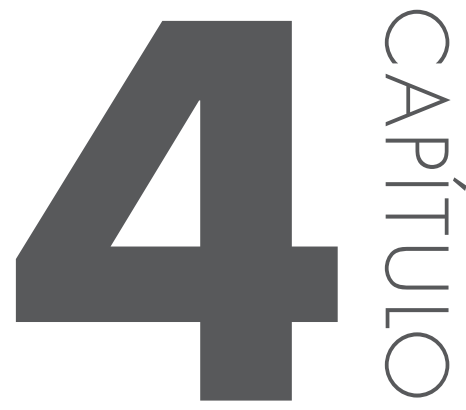

\title{
ANÁLISE DOS POLIMORFISMOS \\ A $164 C$ E rs7039217 NO EXON 2 DO GENE PCA3 NO ESTUDO DO CÂNCER \\ DE PRÓstata
}

Santos, I. S. ${ }^{1 *}$;

Nascimento, E. S.';

Araújo, T.G.2;

Goulart, L. R. ${ }^{2}$;

Neves, A. F.'

' Universidade Federal de Goiás, Departamento de Ciências Biológicas, Laboratório de Genética Molecular e Biotecnologia, Catalão, Goiás, Brasil.

2 Universidade Federal de Uberlândia, Instituto de Genética e Bioquímica, Laboratório de Nanobiotecnologia, Uberlândia, Minas Gerais, Brasil.

\section{*email: souza.irlei@gmail.com}


Resumo: $\bigcirc$ gene PCA3 localiza-se no cromossomo 9q21-22 na posição anti-senso do intron 6 do gene Prune 2. A caracterização da sequência não-codificante do PCA3 demonstrou a presença de moléculas de RNA splicing variantes, bem como locais de poliadenilação alternativas, e alta densidade de stop-codons. Neste momento, o gene PCA3 é o único potencial biomarcador descrito na literatura que demonstra associações com câncer de próstata (CaP). Embora a aplicação diagnóstica do PCA3 tenha sido demonstrada em amostras biológicas importantes, tais como urina, sangue periférico e biópsias, apenas dois estudos têm descrito polimorfismos neste gene; uma repetição "AATA" e um polimorfismo de um único nucleótido (-845G / A) descrito na região promotora. $O$ presente estudo teve como objetivo investigar se os polimorfismos identificados recentemente localizados no exon 2 do gene PCA3 (A164C e dbSNP7039217) estava envolvidos na susceptibilidade ao adenocarcinoma de próstata. DNA genômico total foi extraído a partir de sangue periférico de 89 pacientes com CaP, e subsequentemente submetidos a PCR-RFLP, utilizando as enzimas de restrição Mbol e Tsp45I. Os produtos amplificados foram analisados em eletroforese em gel de agarose e fotodocumentados. A análise estatística foi realizada utilizando GraphPad Prism 5.0. Não foi encontrada correlação significativa entre - polimorfismo A164C e dbSNP7039217 PCA3 e os dados clínicos dos pacientes. Esta é a primeira descrição de análise de SNPs A164C e dbSNP7039217 em regiões PCA3 exon demonstrando sua associação com a progressão do câncer de próstata.

\section{Palavras-chave: PCR-RFLP; Hiperplasia Prostática Benigna; Marcadores Moleculares}




\section{Introduc̣ão}

A próstata consiste em uma glândula exócrina presente no sistema reprodutor masculino, sendo responsável pela produção de $50-70 \%$ dos fluidos seminais (RÖNNAU et. al., 2014). Atualmente existem apenas três processos patológicos que afetam a glândula prostática com considerável frequência, sendo elas: inflamação, aumento nodular benigno e tumores (BRITO; MORAIS, 2012). Dentre estes processos o carcinoma prostático compreende numa lesão extremamente comum em homens, necessitando deste modo, exames minuciosos (EPSTEIN, 2010). 
O Câncer de Próstata (CaP) é considerado o tipo mais comum de tumor que afeta homens americanos e brasileiros, sendo a segunda maior causa de morte por neoplasia (SIEGEL et al., 2012). No Brasil, o CaP consiste no segundo mais comum entre os homens, em valores absolutos, sendo o sexto tipo mais comum no mundo e o mais prevalente em homens, representando cerca de 10\% do total de cânceres, perdendo apenas para o câncer de pele não-melanoma (INCA, 2013).

Conforme salientado pelo Instituto Nacional do Câncer (2013), estima-se para o Brasil no ano de 2014 um valor de aproximadamente 576 mil novos casos de cânceres incluindo o de próstata, pulmão e bexiga. Dentre os fatores de risco aceitos que amplamente associam ao CaP estão a idade, etnia, a dieta e o estilo de vida (MAHMOUD et al., 2013).

O CaP é conhecido como uma doença da terceira idade (BRAWLEY et al., 2009) onde o único fator de risco bem estabelecido para o seu desenvolvimento é a idade. Logo, tem-se notado uma estreita relação entre o aumento da idade e maior risco de desenvolver o CaP, sendo que aproximadamente $0,6 \%$ de todos os casos são diagnosticados antes dos 45 anos, e entre $62 \%$ e $85 \%$, após a idade de 65 anos (FOURNIER et al., 2004; PLATZ; GIOVANNUCCI, 2006). No que se refere à incidência anual do CaP, uma relação significativa foi observada quando considerado a idade dos enfermos em diferentes países bem como os grupos étnicos e raciais (PLATZ; GIOVANNUCCI, 2006; BOYLE; LEVIN, 2008; KARIM-KOSS et. al., 2008; FERLAY et al., 2010).

A etiologia apresentada pelo $\mathrm{CaP}$ envolve causas multifatoriais, como fatores ambientais, hormonais e hereditários (CLARKE et al., 2009). De acordo com PORKKA e colaboradores (2004) o CaP é proveniente de alterações genéticas que atuam inativando genes supressores de tumor e em contrapartida tem-se a ativação de proto-oncogenes. Quando o paciente apresenta metástases, o câncer de próstata demonstra sítios primários de instalação de suas células prostáticas comumente nos ossos, reto, bexiga e linfonodos (GABRIEL; BERNARDES, 2010), o que compromete a qualidade de vida dos pacientes que a possui.

Segundo o INCA (2003) a incidência do CaP vem demonstrando um rápido crescimento, podendo desta maneira ser atribuído em parte, à introdução de modalidades diagnósticas como a utilização do teste do PSA e ao aumento da expectativa de vida da população. No entanto até o presente momento não existe ainda disponiveis testes específicos para o CaP (KLECKA et al., 2010). Atualmente a detecção precoce do CaP é baseada na medição total do soro do antígeno prostático específico (†PSA) e, como complemento o exame retal digital (DRE) acompanhado de biópsia (SUZUKI et al., 2008). Embora o PSA tenha sido utilizado para o diagnóstico por mais de 30 anos, o mesmo apresenta comumente em seus resultados elevado número de falsos-negativos e falsos-positivos (KLECKA et al., 2010).

Apesar da medição do PSA ser considerado como o melhor marcador tumoral do soro convencional disponível, este não apresenta alta especificidade e sensibilidade para o diagnóstico precoce do CaP (ZHOU et al., 2011). Pesquisas do Serviço de Prevenção dos Estados Unidos indicou que o rastreamento do câncer de próstata pelo PSA foi 
associado com mais prejuízos do que benefícios para os pacientes, devido ao excesso de resultados falsos-positivos nos testes, culminando em tratamentos desnecessários $/ \mathrm{CHOU}$ et al., 2011 1). Portanto, são necessários métodos que possam detectar o fumor inicial, num momento em que o tumor é ainda localmente confinado e potencialmente curável (DE KOK et al., 2002).

Considerado como a principal molécula estreitamente associada ao CaP, estudos tem demonstrado o potencial uso do PCA3 quando em conjunto aos níveis de PSA no soro para o diagnóstico do adenocarcinoma da próstata (SALAMI, et al. 2011). Até o momento o gene PCA3 tem se constituído como um potencial biomarcador no diagnóstico do $\mathrm{CaP}$, proporcionando uma base forte para o desenvolvimento de novas estratégias de tratamento (HESSELS et al., 2003).

A molécula de RNA do PCA3 é não codificante (ncRNA) apresentando aumentos significativos em células tumorais prostáticas hormônio dependentes, gerando a hipótese de um papel funcional dessa molécula na biologia da próstata (SCHALKEN et al., 2003). O acentuado aumento do RNA do PCA3 e sua expressão prostática específica no CaP sugerem uma regulação transcricional única (ZHOU et al., 2011), onde o ncRNA é altamente superexpresso em mais de $95 \%$ dos cânceres de próstata primários (BUSSEMAKERS et al., 1999).

A atividade específica do promotor PCA3 em células de CaP pode ser utilizado como uma estratégia adicional para as abordagens terapêuticas específicas (FAN et al., 2010), de modo que as diferenças apresentadas na expressão gênica podem ajudar a elucidar o microambiente do tumor (SALAGIERSKI et al., 2010). Em fevereiro de 2012, a FDA (Food and Drug Administration) aprovou o uso do biomarcador PCA3 no diagnóstico do CaP em urina a partir da detecção de RNA expressos desse gene.

Em suma, estudos utilizando as técnicas de Genética Molecular têm demonstrado que os níveis do ncRNA do gene PCA3 é significativamente aumentado no adenocarcinoma de próstata. Dentre as aplicações clínicas potenciais para o PCA3 destacam-se a deteç̧ão de recorrência local após prostectomia radical ou radioterapia e - monitoramento de pacientes que fazem $\bigcirc$ uso de medicações que afetem PSA (HESSELS; SCHALKEN, 2009).

Embora, a sua aplicação diagnóstica demonstra ser uma ferramenta importante à prática clínica, em amostras biológicas como urina (HESSELS et al., 2003), sangue periférico (OLIVEIRA et al., 2003; NEVES et al., 2012) e biópsias (NEVES et al., 2008; NEVES et al., 2012), até o presente momento, apenas dois trabalhos foram publicados no pubmed (NCBI) relatando associações entre os polimorfismos presentes na sequência de DNA do gene PCA3 e o CaP (ZHOU et al., 2011; FONTENETE et al., 2012). Em ambos os trabalhos foram relatadas associações entre polimorfismos localizados na região promotora do gene com o risco ao desenvolvimento do câncer de próstata. ZHOU e cols. (2011) e FONTENETE e cols. (2012) analisaram as repetições de tetranucleotídeos e um SNP (G/A), respectivamente, na região promotora.

Diferentes campos da atividade científica e de pesquisas acadêmicas básicas têm utilizado as técnicas de Genética Molecular (ATKINS; CLARK, 2004; COTTON, 1997) 
com vistas à aplicação ao diagnóstico e prevenção de diversas doenças (PASSOSBUENO; MOREIRA, 2004; LINSCOTT, 2002), tais como o câncer (SPIEGELMAN et al., 2000; XIAO; OEFNER, 2001).

Técnicas de biologia molecular constituem como um instrumento fundamental na área de genética humana, auxiliando no diagnóstico de doenças monogênicas, permitindo não só a identificação do gene afetado, mas também da mutação responsável pela doença. Não obstante grande parte dos testes genéticos destina-se ao diagnóstico e prevenção de doenças raras, embora avanços tecnológicos tenham consentido o uso destes testes para a avaliação de risco de doenças como câncer (SPIEGELMAN et al., 2000; XIAO; OEFNER, 2001).

A correlação entre mutações gênicas e suscetibilidade a doenças é particularmente importante no câncer, sendo que cerca de $5 \%$ a $10 \%$ dos casos ocorrem em indivíduos que herdaram alguma predisposição a essa doença (MOLINA; TOBO, 2004). Assim, técnicas de biologia molecular como PCR-RFLP, PCR-SSCP, sequenciamento direto e genotipagem de SNPs por PCR em Tempo Real têm sido utilizadas para as análises de polimorfismos gênicos.

No genoma humano os SNPs (Single Nucleotide Polymorphisms) são considerados como a forma mais frequente de variação na sequência de DNA (TAILONMILLER et al. 1999) e são geralmente definidos como regiões pontuais do DNA, onde a base nucleotídica seja variável na população. De acordo com Kwok e Gu (1999), estudos envolvendo análises genotípicas de portadores e não portadores de doença permitem observar genótipos estreitamente associados com indivíduos afetados, indicando um possível gene candidato para a doença em questão.

Os SNPs têm ganhado grande ênfase como um importante marcador utilizado nas pesquisas de doenças genéticas complexas (KWOK; GU, 1999). A análise de SNPs pode ser realizada usando as técnicas de PCR (Polymerase Chain Reaction) seguida pela digestão do DNA com enzimas de restrição específicas (RFLP - Restriction Fragment Length Polymorphism). Dentre as diversas técnicas de biologia molecular, a RFLP é empregada na análise de polimorfismos obtidos através do corte de fragmentos de DNA com endonucleases de restrição.

A técnica de PCR-RFLP tem sido bastante utilizada em trabalhos que visam encontrar diversidade genômica (SCHOGL, 2000). As variações detectadas pela técnica RFLP decorrem de mutações simples, rearranjos dos segmentos de DNA por efeito de deleções, inserções ou translocações e recombinação. Essas modificações podem ocasionalmente alterar a sequência ou substituir bases nitrogenadas em um ou mais sítios de reconhecimento de uma determinada enzima (CAIXETA et al., 2009).

Diante do exposto, o presente trabalho teve como objetivo analisar os polimorfismos A164C e dbSNP7039217 localizado no exon 2 do gene PCA3 a fim de se caracterizar novos locos genéticos de susceptibilidade ao adenocarcinoma de próstata por meio de análises de mutações pontuais do tipo SNPs. 


\section{Material e métodos}

Os procedimentos empregados neste estudo para manipulação do material biológico adotaram as normas do Código de Ética Médica, com No. 005/2001 de aprovação no Comitê de Ética em Pesquisa da Universidade Federal de Uberlândia (UFU). A identificação das amostras foi feita conforme os números de prontuários e o número de entrada do indivíduo na pesquisa.

Neste estudo foram analisadas amostras de pacientes com CaP $(n=89)$ e hiperplasia prostática benigna (HPB) $(n=39)$ e 24 indivíduos da população masculina. Para o polimorfismo A $164 \mathrm{C}$ foi analisado 69 amostras de pacientes com CaP, $33 \mathrm{com}$ HPB e 17 indivíduos da população masculina e para o polimorfismo dbSNP7039217 foram analisados 20 amostras de pacientes com CaP, 6 com HPB e 7 indivíduos da população masculina, provenientes do banco de amostras do Laboratório de Nanobiotecnologia da UFU, coletadas entre 2003-2007 pela equipe médica e ambulatorial do setor de Urologia no Hospital das Clínicas da UFU, mediante autorização dos pacientes, os quais assinaram um Termo de Consentimento. As amostras representando a população masculina brasileira foram provenientes de indivíduos com idade mínima de 20 anos, e que não demonstraram a doença.

$O$ designer dos primers foi realizado utilizando sequências previamente depositadas do gene no GenBank, disponíveis no site do NCBI (www.ncbi.nlm.nih.gov) e com o auxílio do software Primer Express versão 3.0 - Applied Biosystems. A amplificação da sequência alvo do gene PCA3 foi feita a partir de 100ng de DNA genômico dos pacientes, $1,5 \mathrm{mM}$ de $\mathrm{MgCl}_{2}$, 10 pmol de primers, $0,2 \mathrm{mM}$ de dNTPs e $1 \mathrm{U} / \mu \mathrm{L}$ de Taq DNA polimerase.

Após reação otimizada em termociclador, os produtos obtidos foram analisados em gel de agarose a $1,2 \%$ e fotodocumentados por meio do software Loccus Biotecnologia - LPix. O produto amplificado foi digerido com as enzimas Mbol e Tsp45I $(3 \mathrm{U} / \mu \mathrm{L})$ por 4 horas a $37^{\circ} \mathrm{C}$ utilizando a técnica RFLP, para os polimorfismos $\mathrm{A} 164 \mathrm{C}$ e dbSNP7039217, respectivamente.

As análises estatísticas dos dados foram realizadas no programa GraphPad Prism 5.0 (San Diego, CA, USA) utilizando testes de correlação de Spearman e de equilíbrio de Hardy-Weinberg, assim como, o teste do $\chi 2$-quadrado ou Exato de Fisher quando apropriado, e chances de ocorrência da doença (OR). Os valores de " $p$ " menores que 0,05 foram considerados significativos.

\section{Resulfados}

A amplificação do polimorfismo A164C e dbSNP/rs7039217 do exon 2 do gene PCA3 estão representados na Figura 1. 


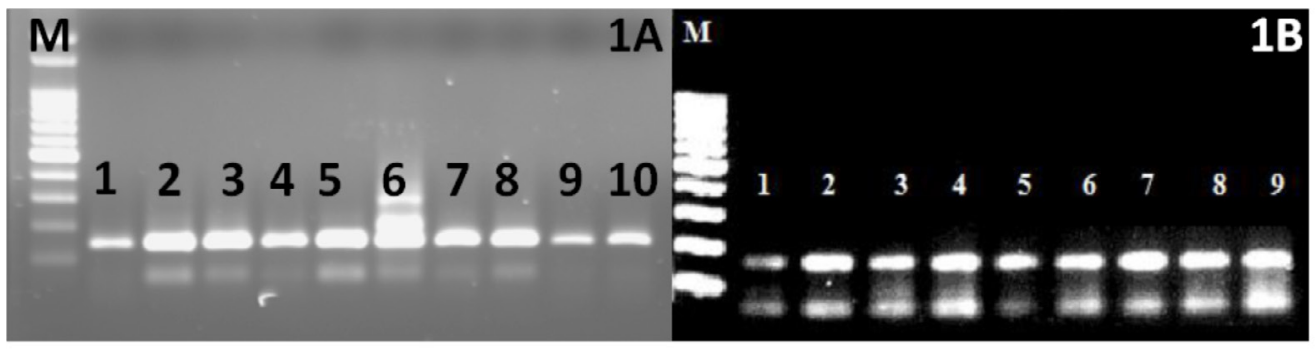

Figura 1: Representação da amplificação do polimorfismo A164C e dbSNP/rs7039217 localizados no exon 2 do gene PCA3. Fig. 1A) As 10 amostras presentes no gel apresentam o fragmento amplificado do tamanho esperado de $188 \mathrm{pb}$. Fig. 1B) As 9 amostras presentes no gel apresentam o fragmento amplificado do tamanho esperado de $165 \mathrm{pb}$. M-Marcador de peso molecular de $100 \mathrm{pb}$.

Três padrões de bandas polimórficas do A164C foram obtidos, sendo correspondentes aos genótipos AA (188pb), AC (188 pb, 154pb e 34pb) e CC (154pb e $34 \mathrm{pb}$ ) (Figura 2a). Para o polimorfismo dbSNP/rs7039217 foi obtido um padrão de banda polimórfica correspondente ao genótipo CC (77pb e 88pb) (Figura 2b).

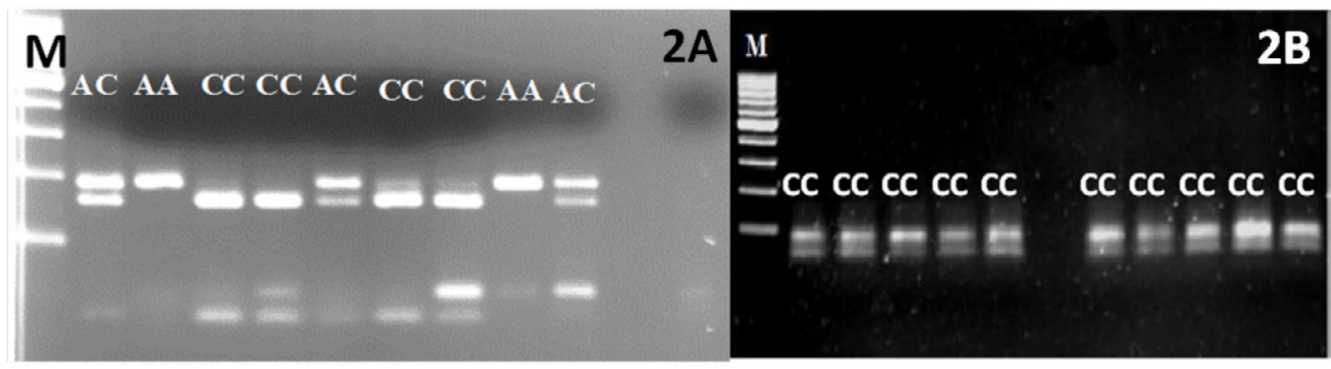

Figura 2: PCR-RFLP representativa do padrão de restrição obtido para o polimorfismo A $164 \mathrm{C}$ e dbSNP/rs7039217 localizados no exon 2 do gene PCA3 gerado pela enzima Mbol e Tsp45I. A) Os fragmentos observados foram correspondentes aos genótipos AA (188pb), AC (188 $\mathrm{pb}, 154 \mathrm{pb}$ e $34 \mathrm{pb}$ ) e CC (154pb e 34pb). B) Os fragmentos correspondentes ao genótipo CC (77pb e $88 \mathrm{pb}$ ). M-Marcador de peso molecular de $100 \mathrm{pb}$

A população estudada para o polimorfismo A164C encontra-se em equilíbrio de Hardy-Weinberg $(\chi 2=1,01 ; P=0,062)$, apresentando frequência genotípica de $49 \%$ AC, $40 \%$ CC e $30 \%$ AA e frequência alélica $46 \%$ A e $54 \%$ C. A idade média apresentada pelos pacientes com genótipo AA foi de 67 anos (SD \pm 7 variando de 58 a 85 anos), de 64 anos (SD \pm 8 , variando de 44 a 82 anos) para indivíduos $A C$ e para o grupo CC foi de 65 anos (SD \pm 9 , variando de 41 a 82 anos). A idade média do grupo populacional masculino com genótipo AA foi de 35 anos $(S D \pm 9$, variando de 25 a 47 
anos), de 42 anos ( $S D \pm 8$, variando de 28 a 55 anos) para indivíduos $A C$, e para o grupo CC foi de 63 anos (SD \pm 0 ).

Para o polimorfismo dbSNP7039217 a população estudada apresenta frequência genotípica de $100 \%$ CC e frequência alélica 100\% C. A idade média demonstrada pelos pacientes com genótipo CC foi de 66anos (SD \pm 7 , variando de 59 a 73 anos). Nenhuma correlação significativa foi encontrada entre os polimorfismo A164C e dbSNP7039217 do PCA3 e os dados clínicos dos pacientes $(p<0,05)$.

Dentre os dados clínicos dos pacientes com CaP e HPB analisados para o polimorfismo dbSNP7039217, 27,27\% apresentaram PSA $<5 \mathrm{ng} / \mathrm{mL}, 50 \%$ demonstraram PSA entre $5-10 \mathrm{ng} / \mathrm{mL}, 22,72 \%$ evidenciaram PSA $>10 \mathrm{ng} / \mathrm{mL}$. Em relação a pacientes com CaP, 55\% possuíam Gleason $<7$ e $45 \%$ apresentaram Gleason 27. No que se refere ao TNM $85 \%$ demonstraram pT1-pT2 e 15\% apresentaram pT3.

As frequências genotípicas e alélicas apresentadas pelo grupo de pacientes com HPB analisados para o polimorfismo A $164 \mathrm{C}$ foram significativamente diferentes daqueles apresentados pelos indivíduos da população masculina $(\chi 2 ; p<0,05)$, por outro lado não foram encontradas diferenças entre os grupos CaP e HPB.

A partir dos dados obtidos foi verificada uma associação positiva entre o genótipo $C C$ versus $A A+A C$ e uma chance 6.25 aumentada de ocorrência do HPB comparado ao grupo populacional masculino. Uma tendência de significância foi encontrada de 2.38 para ocorrência do CaP comparado ao grupo populacional masculino. Embora tenham sido encontradas associações significativas para o genótipo $\mathrm{CC}$ apenas quando considerados valores entre pacientes HPB e grupos de indivíduos da população masculina (OR: 6,25; $P<0,04)$.

\section{Discussão}

Embora o PSA seja um biomarcador específico da próstata, o mesmo não apresenta especificidade ao adenocarcinoma de próstata uma vez que outras enfermidades benignas que acometem esta glândula provocam o seu aumento no soro, por conseguinte a maioria dos casos de homens com altos índices de PSA não demonstram ter o CaP (LOEB; CATALONA, 2008). Devido a este fato, têm sido propostos inúmeros estudos visando modificações nas medições do PSA a fim de promover melhorias no desempenho das análises e no diagnóstico (LIN, 2009).

Assim sendo, existe uma extrema necessidade do uso de biomarcadores de alto desempenho como uma ferramenta complementar ao PSA no intuito de distinguir com maior precisão e especificidade os pacientes com câncer dos saudáveis, não obstante o emprego desta abordagem propiciará ainda a identificação de enfermos cujo câncer apresenta-se agressivo com alta precisão, minimizando deste modo a grande quantidade de biopsias desnecessárias (FONTENETE et al., 2011). 
Uma vez que o CaP se configura como uma doença heterogênea, a utilização de um painel de biomarcadores pode aprimorar ainda mais a precisão do diagnóstico (SALAGIERSKI et al., 2010), de modo que o uso de biomarcadores com finalidade de triagem, detecção e prognóstico do $\mathrm{CaP}$, revolucionou o manejo desta doença (SCHIFFER, 2007). Atualmente uma ampla gama de estudos aferem biomarcadores na urina podendo ser utilizados na detecção de células cancerígenas ou de produtos prostáticos que podem indicar a presença do CaP (DOWNES et al., 2007), bem como a detecção do PCA3 no sangue que pode potencialmente ser utilizado como um indicador prognóstico de câncer de próstata agressivo (JOST et al., 2010).

Em fevereiro de 2012, a FDA (Food and Drug Administration) aprovou o uso do biomarcador PCA3 no diagnóstico do CaP em urina. Dentre as aplicações clínicas potenciais para o PCA3 destacam-se a detecção de recorrência local após prostectomia radical ou radioterapia e o monitoramento de pacientes que fazem o uso de medicações que afetem PSA (HESSELS; SCHALKEN, 2009). Os testes com base na detecção do PCA3 em suma podem ser de grande auxílio ao PSA, uma vez que quando combinados (PCA3, PSA e biópsia), há um significativo aumento de $90 \%$ na acurácia diagnóstica na predição da extensão extracapsular ou clinicamente o baixo volume do fumor (WHITMAN et al., 2008).

O acentuado aumento do RNA do PCA3 no CaP e sua expressão próstataespecífica (BUSSEMAKERS et al., 1999) indica que os estudos de alterações genéticas tais como análises de polimorfismos podem ser úteis na elucidação da patogênese do CaP, assim como sobre o papel funcional do PCA3 nas células tumorais prostáticas.

Estudos a cerca de polimorfismos de nucleotídeo único (SNP) são amplamente úteis na pesquisa genética, uma vez que permitem rastrear genes causadores de doenças por meios de análises de ligação familiar. Os SNPs consistem na mudança de um único nucleotídeo e são as formas mais abundantes de variação genética, com frequência no genoma de um SNP a cada 1.000 pares de base (JOHNSON et al., 2004). Assim, a análise de SNPs e haplótipos na investigação oncológica pode auxiliar na melhoria das técnicas de diagnóstico e para o desenvolvimento de agentes para a prevenção e o tratamento do câncer (FONTENETE et al., 2012).

Os SNPs são resultantes de mutações sendo herdados como variantes alélicas, podendo ou não gerar diferenças fenotípicas (HAYASHI et al., 2004). Uma vez que constituem as formas mais abundantes de variações do genoma, os SNPs podem ser utilizados na análise e caracterização genética (RAFALSKI, 2004). Estudos a cerca de SNPs que alteram a expressão do gene PCA3 pode ser útil para o diagnóstico clínico do câncer de próstata, como descrito por outros autores (NAKANISHI et al., 2008; HESSELS; SCHALKEN 2009; AUBIN et al., 2010; KLECKA et al., 2010).

Os estudos de polimorfismos presentes nas sequências do gene têm demonstrado ser de suma importância na nova abordagem de fatores hereditários de predisposição ao CaP com ênfase na molécula do PCA3, sendo que estudos prévios evidenciaram uma estreita relação entre SNPs e a região promotora deste gene. De acordo com ZHOU e 
colaboradores (2011) o polimorfismo de repetição "TAAA" na região promotora do gene PCA3 está relacionado ao risco de CaP.

Os indivíduos analisados para o polimorfismo dbSNP/rs7039217 exibiram genótipo selvagem quando verificado os padrões de bandas obtidos, assim como dados obtidos na Europa, Ásia e África Sub-Saariana depositados no banco de SNPs do NCBI (National Center for Biotechnology Information). Por conseguinte devido todos os indivíduos de ambos os grupos (HPB, CaP e população masculina) apresentarem genótipo normal não se fez necessário a continuidade do experimento para este sítio polimórfico. Os dados obtidos para o polimorfismo A164C sugere associação com o desenvolvimento de doenças prostáticas, corroborando com dados obtidos por Zhou e cols. (2011) e Fontenete e cols. (2012), demonstrando haver associações entre polimorfismos localizados na região promotora do gene ou em regiões de exon com o risco ao desenvolvimento e/ou progressão do CaP.

A diferença de susceptibilidade pode estar relacionada às alterações na frequência alélica do SNP rs 1417360 (A/C) do PCA3 encontrada entre pacientes com $\mathrm{CaP}, \mathrm{HPB}$, bem como, com os grupos de indivíduos populacional. Os níveis de RNA do PCA3 aumentados no CaP já se encontram bem estabelecidos na literatura quando comparado aos indivíduos saudáveis ou com HPB. No presente trabalho, nós demonstramos que o $\mathrm{dbSNP/rs7039217} \mathrm{não} \mathrm{apresentou} \mathrm{diferenças} \mathrm{polimórficas} \mathrm{entre} \mathrm{os}$ grupos de indivíduos analizados, em que todos apresentaram o genótipo selvagem com sítio de corte para a enzima de restrição, ou seja genótipo $C C(C / T)$. Já o SNP rs 1417360 localizado no exon 2 do gene PCA3 apresentou no nosso estudo associação com $\circ \mathrm{CaP}$, e a partir desses dados hipotetizamos que o alelo $\mathrm{C}$ possa atuar como uma região acentuadora para o aumento da expressão do PCA3 e/ou contribua para uma maior estabilidade do RNA.

Contudo, é importante enfatizar nesta última hipótese que o exon 2 sofre splicing em $95 \%$ dos casos que apresentam PCA3 positivos associados ao CaP, e a maneira na qual o exon 2 estaria envolvido na associação com o adenocarcinoma de próstata ainda consiste em um desafio a ser elucidado. Considerando a análise que fizemos não é possível afirmar que a mudança $\mathrm{A} / \mathrm{C}$ no polimorfismo $\mathrm{A} 164 \mathrm{C}$ module a expressão do PCA3 e se faz necessário estudos de diferentes tipos de polimorfismos nesse gene que possam auxiliar na compreensão de como essas alterações genéticas estão envolvidas na susceptibilidade de ocorrência e/ou progressão do CaP, sendo fundamental maiores estudos prospectivos.

Dentre as limitações do presente trabalho podemos citar o pequeno tamanho populacional e o estudo com uma população altamente miscigenada como a brasileira. Assim, estudos adicionais com populações de diferentes etnias e um maior número amostral são necessários para fornecer uma visão mais aprofundada dos nossos resultados inéditos, mas preliminares. Em suma, nosso estudo apresenta-se como um veiculador de conhecimento e informação, no qual demonstra uma associação entre o polimorfismo genético A $164 \mathrm{CA} / \mathrm{C}$ no exon 2 do PCA3 e o CaP na população brasileira, 
sugerindo que essa região possa ser de susceptibilidade genética ao $\mathrm{CaP}$ e pode desempenhar um papel importante como estudo piloto para a compreensão do adenocarcinoma de próstata.

\section{Conclusão}

Os dados apresentados nesse trabalho são inéditos para análise dos polimorfismos SNP rs7039217 e A164C localizados em exons do gene PCA3 no estudo da progressão do adenocarcinoma de próstata, demonstrando não haver diferença de susceptibilidade relacionada à frequência alélica do SNP rs7039217 (C/T) do PCA3 entre pacientes com CaP, HPB e população masculina, não associando ao adenocarcinoma de próstata, bem como $\circ \mathrm{HPB}$. Entretanto o polimorfismo A164C apresentou haver associação entre a alteração $A / C$ com $\circ$ CaP comparado ao grupo popacional masculino. As informações aqui alcançadas permitem uma melhor compreensão a cerca do gene PCA3, assim como, na caracterização de polimorfismos existentes ao longo de sua sequência, e nas possíveis influencias de tais SNP na biologia da próstata uma vez que estudos prévios relatam uma estreita ligação deste gene com o adenocarcinoma de próstata. 


\title{
Polymorphism A164C and RS7039217 analysis in exon 2 of the PCA3 gene in the study of prostate cancer
}

\begin{abstract}
The PCA3 gene is located on chromosome 9q2 1-22 in an antisense orientation within the intron 6 of the Prune 2 gene. The characterization of the non-coding PCA3 transcript sequence demonstrated the presence of RNA molecules with splicing variants as well as alternative polyadenylation sites, and high density of stop-codons. At the moment, the PCA3 gene is the unique potential biomarker described in the literature presenting associations with prostate cancer $(\mathrm{PCa})$. Although the PCA3 diagnostic application have been demonstrated in important biological samples such as urine, biopsies and peripheral blood, only two studies have described polymorphisms in this gene; a "TAAA" repeat and a single nucleotide polymorphism $(-845 \mathrm{G} / \mathrm{A})$ described in the promoter region. The present study aimed to investigate if a recently identified polymorphism located at the exon 2 of PCA3 gene (A164C and dbSNP7039217) was involved in the susceptibility to prostate adenocarcinoma. Total genomic DNA was extracted from peripheral blood of 89 PCa patients, subsequently subjected to PCR-RFLP using the Mbol and Tsp45I restriction enzyme. Amplified products were analyzed in agarose gel electrophoresis and photodocumented. Statistical analysis was performed using GraphPad Prism 5.0. No significant correlation was found between the A164C polymorphism and dbSNP7039217 PCA3 and the clinical data of patients. This is the first description of a SNPs A 164C and dbSNP7039217 analysis in PCA3 exon regions demonstrating its association with prostate cancer progression.
\end{abstract}

Keywords: PCR-RFLP; Benign Prostatic Hyperplasia; Molecular Markers.

\section{Referências bibliográficas}

ATKINS, S.D.; CLARK, I.M. Fungal molecular diagnostics: a mini review. J Appl Genet. 2004; 45(1):3-15.AUBIN, S.M.; REID, J.; SARNO, M.J.; et al. (2010). PCA3 molecular urine test for predicting repeat prostate biopsy outcome in populations at risk: validation in the placebo arm of the dutasteride REDUCE trial. J Urol 184:1947-1952.

BOYLE, P.; LEVIN, B. World cancer report 2008. Lyon: IARC Press; 2008. 510p. 
BRAWLEY, O. W.; ANKERST, D. P.; THOMPSON, I. M. Screening for prostate cancer. CA Cancer J Clin 59:264-273, 2009.

BRITO, S. F. S.; MORAIS, V. Câncer de Próstata: Caracterização Epidemiológica e Riscos Hereditários. Revista Eletrônica Acervo Saúde. v. 4, n. 1, p. 247-257, 2012.

BUSSEMAKERS, M. J. G; VAN BOKHOVEN, A.; VERHAEGH, G. W.; SMITH, F. P.; KARTHAUS, H. F. M; SCHALKEN, J. A.; DEBRUYNE, F. M. J; RU. N.; ISAACS, W. B. DD3: A new prostate-specific gene, highly overexpressed in prostate cancer. Cancer Res 59: 5975-5979, 1999.

CAIXETA, E. T.; et. al. Tipos de marcadores moleculares. In: BORÉM, A.; CAIXETA, E. T. (Ed.). Marcadores moleculares. 2. ed. Viçosa: UFV, p. 11-93, 2009.

CHOU, R.; CROSWELL, J.M.; DANA, T.; BOUGATSOS, C.; BLAZINA, I.; FU, R.; et al. Screening for prostate cancer: a review of the evidence for the U.S. Preventive Services Task Force. Ann Intern Med. 155:762-71, 2011.

CLARKE, R. A.; ZHAO, Z.; GUO, A. Y.; ROPER, K.; TENG, L.; et al. (2009) New Genomic Structure for Prostate Cancer Specific Gene PCA3 within BMCC1: Implications for Prostate Cancer Detection and Progression. PLoS ONE 4(3): e4995. doi:10.1371/journal.pone.0004995

COTTON, R.G.H. Slowly but surely towards better scanning for mutations. TIG. 1997; 13(2):43-6.

DE KOK, J.B.; VERHAEGH, G.W.; ROELOFS, R.W.; et al. DD3(PCA3), a very sensitive and specific marker to detect prostate tumors. Cancer Res $2002 ; 62: 2695-8$.

DOWNES, M.R.; BYRNE, J.C.; PENNINGTON, S.R.; DUNN, M.J.; et al. Urinary markers for prostate cancer. BJU Int. 2007; 99: 263-8.

EPSTEIN, J. I. O trato uninário inferior e sistema genital masculino. In: KUMA, V. et al. Patologia: bases patológicas das doenças. 8. ed. Rio de Janeiro: Elsevier, 2010.

FAN, J. K.; WEI, N.; DING, M.; GU, J. F.; LIU, X. R.; LI, B. H.; QI, R.; HUANG, W. D.; LI, Y. H.; $X I O N G, X . Q$, et al: Targeting Gene-ViroTherapy for prostate cancer by DD3-driven oncolytic virusharboring interleukin-24 gene. Int J Cancer 2010, 127(3):707-717.

FERLAY, J.; PARKIN, D.M.; STELIAROVA-FOUCHER, E. (2010). Estimates of cancer incidence and mortality in Europe in 2008. Eur J Cancer: 46:765-81. 
FONTENETE, S.; SILVA, J.; TEXEIRA, A.L.; RIBEIRO, R.; BASTOS, E.; PINA, F.; MEDEIROS, R. Controversies in using urine samples for Prostate Cancer detection: PSA and PCA3 expression analysis. Clinical Urology. International Braz J Urol, v. 37, n.6, p.719-726, November - December 2011.

FONTENETE, S.; NOGUEIRA, A.; PINA, F.; LOBO, F.; FRAGA, A.; SILVA, F. C.; MEDEIROS, R. Molecular Study of the PCA3 Gene: Genotypic Analysis of PCA3 Polymorphism -845G > A and Metastatic Prostate Cancer. Genetic Testing and Molecular Biomarkers, v. 16, n. 5, 2012.

FOURNIER, G.; VALEI, A.; MANGIN, P.; CUSSENOT, O. (2004). Prostate cancer. Epidemiology. Risk factors. Pathology. Ann Urol, Paris: 38:187-206.

GABRIEL, S.A.S.; BERNARDES, S.A.M.S (2010). A Importância da Detecção Precoce e Prevenção do Câncer de Próstata. Trabalho apresentado como requisito parcial para obtenção de título Técnico em Enfermagem, Instituto Federal de Educação Ciência e Tecnologia do Sul de Minas, 2010.

HAYASHI, K.; HASHIMOTO, N.; DAIGEN, M.; ASHIKAWA, I. Development of PCR-based SNP markers for rice blast resistance genes at the Piz locus. Theor Appl Genet, 108(7): 1212-20, 2004.

HESSELS, D.; KLEIN GUNNEWIEK, J. M.; VAN OORT, I.; KARTHAUS, H. F.; VAN LEENDERS, G. J.; VAN BALKEN, B.; et al (2003). DD3 (PCA3)-based molecular urine analysis for the diagnosis of prostate cancer. Eur Urol 44, 8-15; discussion 15-16.

HESSELS, D.; SCHALKEN, J.A. (2009) The use of PCA3 in the diagnosis of prostate cancer. Nat Rev Urol 6:255-261.

INSTITUTO NACIONAL DO CÂNCER. Estimativas da incidência e mortalidade por câncer. Ministério da Saúde, Rio de Janeiro 2003.

INSTITUTO NACIONAL DO CÂNCER. Estimativa 2014: incidência de câncer no Brasil. Ministério da Saúde, Rio de Janeiro 2013.

JOHNSON, V. J.; YUCESSOY, B.; LUSTER, M. I: Genotyping of single nucleotide polymorphisms in cytokine genes using real-time PCR allelic discrimination technology. Cytokine, 27: 135-141, 2004.

JOST, M.; DAY, J.R.; SLAUGHTER, R.; KORECKIJ, T.D.; GONZALES, D.; et al. Molecular assays for the detection of prostate tumor derived nucleic acids in peripheral blood. Molecular Cancer 2010, 9:174 
KARIM-KOSS, H.E.; DE VRIES, E.; SOERJOMATARAM, I.; LEMMENS, V.; SIES- LING, S.; COEBERGH, J.W. (2008). Recent trends of cancer in Europe: a combined approach of incidence, survival and mortality for 17 cancer sites since the 1990s. Eur J Cancer: 44:1345-89.

KLECKA, J.; HOLUBEC, L.; PESTA, M.; et al. (2010). Differential display code 3 (DD3/PCA3) in prostate cancer diagnosis. Anticancer Res 30:665-670.

KWOK, P-Y.; GU, Z. Single nucleotide polymorphism libraries: why and how are we building them? Molecular Medicine Today 5: 538-43, 1999.

LIN, D.W. Beyond PSA: utility of novel tumor markers in the setting of elevated PSA. Urol Oncol. 2009; 27: 315-21.

LINSCOTT, A.J. Molecular diagnostics for infections disease. Pathol Case Rev. 2002; 7(2):64-9.

LOEB, S.; CATALONA, W.J.; What to do with an abnormal PSA test. Oncologist. 2008; 13: 299 305.

MAHMOUD, A.M.; et al. (2013). Soy isoflavones and prostate cancer: A review of molecular mechanisms. Journal of Steroid Biochemistry \& Molecular Biology: 140: 116-132.

MOLINA, A.L.; TOBO, P.R. Biologia molecular Parte 2 - Uso das técnicas de biologia molecular para diagnóstico. Einstein. 2004; 2(2):139.

NAKANISHI, H.; GROSKOPF, J.; FRITSCHE, H.A.; et al. (2008). PCA3 molecular urine assay correlates with prostate cancer tumor volume: implication in selecting candidates for active surveillance. J Urol 179:1804-1809; 1809-1810.

NEVES, A. F.; ARAÚJO, T. G.; BIASE, W. K. F. S.; MEOLA, J.; ALCÂNTARA, T. M.; FREITAS, D. G.; GOULART, L. R. Combined analysis of multiple mRNA markers by RT-PCR assay for prostatecancer diagnosis. Clin Biochem 41:1191-1198, 2008.

NEVES, A. F.; OlIVEIRA, J. D. D.; ARAÚJO, T. G.; MARANGONI, K.; GOULART, L. R. PCA3 RNA detection in blood and tissue samples for prostate cancer diagnosis. Clin Chem Lab Med. DOI 10.1515/cclm-2012-039, 2012.

OLIVEIRA, J. D. D.; GOULART, L. R.; OLIVEIRA-JR, W. P.; MEOLA, J.; NEVES, A. F. DD3 gene expression in peripheral blood of patients with prostate cancer and with benign prostate hyperplasia as a molecular diagnostic. Eur Urol Suppl 2:102-102, 2003. 
PASSOS-BUENO, M.R.S.; MOREIRA, E.S. Ferramentas básicas da genética molecular humana. Genômica. São Paulo: Atheneu; 2004. p. 43-67.

PLATZ, E.A.; GIOVANNUCCI, E. (2006). Prostate cancer. In: Schottenfeld D, Fraumeni Jr JF, editors. Cancer epidemiology and prevention. 3rd edition Oxford: Oxford University Press $1128-50$.

PORKKA, K. P.; VISAKORPI, T. Molecular mechanisms of prostate cancer. Eur Urol 45:683-691, 2004.

RAFALSKI, A.; MORGANTE, M. Corn and humans: recombination and linkage disequilibrium in two genomes of similar size. Trends Genet, 20: 103-111, 2004.

RING, H. Z.; KROETZ, D. L. Candidate gene approach for pharmacogenetic studies. Pharmacogenomics 3: 47-56, 2002.

RÖNNAU, C. G. H.; VERHAEGH, G. W.; LUNA-VELEZ, M. V.; SCHALKEN, J. A. Noncoding RNAs as Novel Biomarkers in Prostate Cancer. BioMed Research International. Volume 2014, Article ID 591703;

ROSES, A. D. Pharmacogenetic. Hum Mol Genet 10: 2261-7, 2001. ROSES, A. D. Genomebased pharmacogenetics and the pharmaceutical industry. Nat Rev Drug Discov 1: 541-9, 2002.

SALAGIERSKI, M.; VERHAEGH, G. W.; JANNINK, S. A, et al. (2010). Differential expression of PCA3 and its overlapping PRUNE2 transcript in prostate cancer. Prostate 70:70-78.

SALAMI, S. S.; SCHMIDT, F.; LAXMAN, B.; REGAN, M. M.; RICKMAN, D. S.; SCHERR, D.; et al. Combining urinary detection of TMPRSS2: ERG and PCA3 with serum PSA to predict diagnosis of prostate cancer. Urol Oncol 2011. Epub ahead of print 19 May 2011. DOI:10.1016/j. urolonc. 2011.04 .001 .

SCHALKEN, J. A.; HESSELS, D.; VERHAEGH, G. (2003) New targets for therapy in prostate cancer: differential display code 3 (DD3 (PCA3)), a highly prostate cancer-specific gene. Urology 62: 34-43.SCHLOGL, P. S. Análise da diversidade genética em regiões não codificadoras de DNAs de cloroplastos em Araucaria angusiifolia por PCR-RFLP. 2000. 66 f. Dissertação (Mestrado) - Curso de Biotecnologia, Universidade Federal de Santa Catarina, Florianópolis, 2000.SCHIFFER, E. Biomarkers for prostate cancer. World J Urol. 2007; 25: 557-62.

SCOTT, K. D.; ABLETT, E. M.; LEE, L. S.; HENRY, R. J. AFLP markers distinguishing an early mutant of flame seedless grape. Euphytica, New York, v. 113, n. 3, p. 245-249, 2000. 
SIEGEL, R.; NAISHADHAM, D.; JEMAL, A. Cancer statistics. CA Cancer J Clin. 58:pp. 71-96, 2012.

SPIEGELMAN, J.I.; MINDRINOS, M.N.; OEFNER, P.J. High-accuracy DNA sequence variation screening by DHPLC. Biotechniques. 2000; 29: (5):1084-92.

SUZUKI, H.; FLANIGAN, R.C.; OKUYAMA, A. (2008). American Urological Association: Prostatespecific antigen (PSA)-based screening. Int J Urol 15(9):757-762.

TAILLON-MILLER, E.; PIERNOT, E. E.; KWOK, P-Y. Efficient approach to unique singlar nucleotide polymorphismo discovery. Genome Research 9: 499-505, 1999.

WHITMAN, E.J.; GROSKOPF, J.; ALI A. et al.: PCA3 score before radical prostatectomy predicts extracapsular extension and tumor volume. J Urol. 2008; 180: 1975-8; discussion 1978-9.

$\mathrm{XIAO}$, W.; OEFNER, P.J. Denaturing high-performance liquid chromatography: A Review. Hum Mutat. $2001 ; 17(6): 439-74$.

ZHOU, W.; CHEN, Z.; HU, W.; et al. (2011). Association of short tandem repeat polymorphism in the promoter of prostate cancer antigen 3 gene with the risk of prostate cancer. Plos One 6:e20378. 